AUTHOR CORRECTION OPEN

\title{
Author Correction: Economic analysis of implementing virtual reality therapy for pain among hospitalized patients
}

Sean D. Delshad ${ }^{1,2}$, Christopher V. Almario ${ }^{1,3,4}$, Garth Fuller ${ }^{1}$, Duong Luong ${ }^{5}$ and Brennan M. R. Spiegel ${ }^{1,3,4,6}$

npj Digital Medicine (2018)1:41; doi:10.1038/s41746-018-0044-2

Correction to: npj Digital Medicine https://doi.org/10.1038/ s41746-018-0026-4, Published online 13 June 2018

The author would like to update the competing interest statement, which in the original published article stated "B.M.R.S. has received a research grant, administered by his academic institution, from appliedVR (Los Angeles, California)", to include additional information. The competing interest statement has been changed to "B.M.R.S. received a research grant, administered by his academic institution, and also received $\$ 1250$ in 2014 for a one-time activity that was unrelated to the published research, both from appliedVR (Los Angeles, California)." This has been corrected in the HTML and PDF version of the Article.

\begin{abstract}
Open Access This article is licensed under a Creative Commons Attribution 4.0 International License, which permits use, sharing, adaptation, distribution and reproduction in any medium or format, as long as you give appropriate credit to the original author(s) and the source, provide a link to the Creative Commons license, and indicate if changes were made. The images or other third party material in this article are included in the article's Creative Commons license, unless indicated otherwise in a credit line to the material. If material is not included in the article's Creative Commons license and your intended use is not permitted by statutory regulation or exceeds the permitted use, you will need to obtain permission directly from the copyright holder. To view a copy of this license, visit http://creativecommons. org/licenses/by/4.0/.
\end{abstract}

(c) The Author(s) 2018

${ }^{1}$ Cedars-Sinai Center for Outcomes Research and Education (CS-CORE), Los Angeles, CA, USA; ${ }^{2}$ Department of Medicine, David Geffen School of Medicine at UCLA, Los Angeles, CA, USA; ${ }^{3}$ Division of Digestive and Liver Diseases, Cedars-Sinai Medical Center, Los Angeles, CA, USA; ${ }^{4}$ Division of Informatics, Cedars-Sinai Medical Center, Los Angeles, CA, USA; ${ }^{5}$ Department of Pharmacy, Cedars-Sinai Medical Center, Los Angeles, CA, USA and ${ }^{6}$ Department of Health Policy and Management, UCLA Fielding School of Public Health, Los Angeles, CA, USA

Correspondence: Brennan M. R. Spiegel (Brennan.Spiegel@cshs.org)

Published online: 23 August 2018 